\title{
Prevalence and Correlates of Obesity and Overweight in Tunisian Bipolar I Patients
}

\author{
Asma Ezzaher ${ }^{1,2 *}$, Anwar Mechri ${ }^{2}$, Dhouha Haj Mouhamed ${ }^{1,2}$, Wahiba Douki ${ }^{1,2}$, Lotfi Gaha ${ }^{2}$, \\ Mohamed Fadhel Najjar ${ }^{1}$ \\ ${ }^{1}$ Biochemistry and Toxicology Laboratory, Monastir University Hospital, Monastir, Tunisia; ${ }^{2}$ Research Laboratory "Vulnerability to \\ Psychotic Disorders LR 05 ES 10”, Department of Psychiatry, Monastir University Hospital, Monastir, Tunisia. \\ Email: "ezzaherasma@yahoo.fr
}

Received January $11^{\text {th }}, 2013$; accepted February $12^{\text {th }}, 2013$; accepted March $2^{\text {nd }}, 2013$

Copyright (C) 2013 Asma Ezzaher et al. This is an open access article distributed under the Creative Commons Attribution License, which permits unrestricted use, distribution, and reproduction in any medium, provided the original work is properly cited.

\begin{abstract}
Objective: We aim to determine the prevalence of obesity and overweight in bipolar I patients, and to examine their associations with the demographic, clinical and therapeutic characteristics of this population. Patients and Methods: Our study included 120 bipolar I patients ( 79 men and 41 women, mean age $=39.5 \pm 11.9$ years). Weight and height were evaluated by body mass index (BMI). Obesity was defined when BMI $\geq 30 \mathrm{~kg} / \mathrm{m}^{2}$ and overweight when BMI $\geq 25$ $\mathrm{kg} / \mathrm{m}^{2}$. Results: The prevalence of obesity and overweight was respectively $32.5 \%$ and $30.8 \%$. Obesity was significantly more frequent in women than men. The illness duration was significantly longer in obese patients than in those with normal weight. Moreover, the family history of medical disorders and concomitant medical disorders was significantly more frequent in obese patients than in those with normal weight. However, any significant association between therapeutic characteristics and obesity or overweight was found. Conclusions: Obesity and overweight were frequent in bipolar I patients. Obesity was significantly frequent in women and significantly associated with illness duration, medical disorders, and concomitant medical disorders. These results emphasized the need for specific treatment strategies and programs for weight control for these patients.
\end{abstract}

Keywords: Bipolar I Disorder; Obesity; Overweight

\section{Introduction}

Bipolar disorder (previously also labelled as manic-depressive illness) is typically referred to as an episodic, yet lifelong and clinically severe affective (or mood) disorder, affecting approximately $3.5 \%$ of the population [1-5]. It is a chronic disease that is associated with a potentially devastating impact on patients' wellbeing and social, occupational, and general functioning [6]. The disorder ranks as the sixth leading cause of disability in the world, with an economic burden that in the US alone that is estimated more than a decade ago at $\$ 7$ billion in direct medical costs and $\$ 38$ billion (1991 values) in indirect costs [7].

A number of reviews and studies have shown that people with severe mental illness, including bipolar disorder, have an excess mortality, being two or three times as high as that in the general population. This mortality gap, which translates to a 13 - 30 year shortened life ex-

*Corresponding author. pectancy in severe mental illness patients, has widened in recent decades, even in countries where the quality of the health care system is generally acknowledged to be good. About $60 \%$ of this excess mortality is due to physical illness especially cardiovascular disease [8].

Cardiovascular risk factors in this pathology include nonmodifiable risk factors, such as sex, family history, personal history, and age, as well as such modifiable risk factors as obesity, smoking, diabetes, hypertension, and dyslipidemia [9].

Obesity is the condition of having an abnormally high proportion of body fat. It is most commonly operationally defined as a body mass index (BMI) of 30 or greater. Abdominal obesity reflects fat that is centrally distributed between the thorax and pelvis as opposed to lower body obesity, which reflects fat that is distributed around the hips, thighs, and buttocks. Abdominal obesity is often operationally defined by the waist circumference or the waist-to-hip ratio. In contrast to lower body obesity, abdominal obesity is particularly associated with type 2 
diabetes mellitus, dyslipidemia, hypertension, coronary heart disease, stroke, and early mortality.

Although the pathogenesis of obesity is unknown, it is often viewed as a polygenic, heterogeneous metabolic disorder due to consuming more calories than expended as energy.

Factors etiologically associated with obesity are family history of obesity, overeating, and physical inactivity. Low resting metabolic rate is not thought to play a major role in causing or maintaining most obesity. Of theoretical note, dysfunction in neurotransmitter and neuropeptide systems hypothesized to underlie various mental disorders, including bipolar disorder, has also been hypothesized to be involved in obesity. Implicated shared neurotransmitter systems have included serotonin, dopamine and norepinephrine. Implicated neuropeptides have included corticotrophin-releasing factor and neuropeptide $\mathrm{Y}[10]$.

Our study aims to determine the prevalence of obesity and overweight in patients with bipolar I disorder, and to examine their associations with the demographic, clinical and therapeutic characteristics of this population.

\section{Patients and Methods}

\subsection{Subjects}

Our study included 120 patients with bipolar I disorder from the psychiatry department of the University Hospital of Monastir, Tunisia, aged $39.5 \pm 11.9$ years, 79 men (39.6 \pm 10.9 years) and 41 women ( $39.3 \pm 13.7$ years). Consensus on the diagnosis, according to the Diagnostic and Statistical Manual of Mental Disorders, fourth edition (DSM-IV) criteria [11], was made by psychiatrists. The exclusion criteria were age $<18$ years, other psychiatric illnesses, epilepsy or mental retardation. This study was approved by the local ethical committee and all subjects were of Tunisian origin. Written informed consent was obtained from all voluntary participants.

All subjects were questioned about their age, gender, cigarette and alcohol consumption habits and clinical and therapeutic history. The socio-demographic and clinical characteristics (age at onset, the total number of episodes, number of manic episodes, depressive polarity at index episode, severity of index episode, duration of illness and the number of lifetime suicide attempts) are shown in Table 1.

\subsection{Body Mass Index (BMI) Determination}

BMI was calculated as weight $(\mathrm{kg})$ divided by height $\left(\mathrm{m}^{2}\right)$. For the present study, we adopted the classification of overweight and obesity formalized by the World Health Organization [12]. This classification uses the same cutoff points reported in the evidence-based clinical guidelines for the identification, evaluation, and treatment of over- weight and obesity in adults, published by the National Heart, Lung, and Blood Institute of the National Institutes of Health [13]. Men and women were considered to be underweight if their BMI was less than 18.5, normal weight if their BMI was between 18 and 24.9, overweight if their BMI was between 25 and 29.9, and obese if their BMI was equal to or greater than $30 \mathrm{~kg} / \mathrm{m}^{2}$.

\subsection{Statistical Analysis}

Statistical analyses were performed using SPSS 17.0 (SPSS, Chicago, IL, USA). Quantitative variables were presented as mean $\pm \mathrm{SD}$ and comparisons were performed using the Student's t test. Qualitative variable comparisons were performed using the Chi-squared test $\left(\chi^{2}\right)$ and Fisher's exact test (when $\mathrm{n}<5$ ).

The statistical significance level was set at $\mathrm{P}<0.05$. All variables with a $p$ value $<0.25$ between the two studied groups were considered as potential confounder factors for this analysis.

\section{Results}

In bipolar I patients, the prevalences of obesity and overweight were $32.5 \%$ and $30.8 \%$ respectively (Table 1). Obesity was more frequent in women than men $(46.3 \%$ Vs $25.3 \%, \mathrm{p}=0.04$ ) (Tables 1 and 2). Women have also the highest rate of unemployment $(63.4 \% \mathrm{Vs} 31.6 \%, \mathrm{P}=$ 0.001) (Table 1).

We noted that men were so much more likely to be smokers and alcoholic consumers than women $(91.1 \% \mathrm{VS}$ $2.4 \%, \mathrm{P}<0.0001 ; 57 \%$ Vs $2.4 \%, \mathrm{P}<0.0001)$. In addition, they have the highest number of manic episodes $(3.8 \pm 2.3$ $V_{S} 2.8 \pm 2.6 ; \mathrm{P}=0.04$ ) (Table 1).

We showed that there were no significant differences in demographic characteristics, in terms of age, education years and unemployed status, between study groups (obese, overweight and normal patients). Tobacco and alcoholic use were also not significantly associated with obesity or overweight.

Concerning clinical characteristics, we showed that the duration of disease was longer in obese patients (14.8 \pm 7.8 years) and overweight patients (12.6 \pm 8.4 years) than in those with normal weight $(9.6 \pm 7.7$ years), with significant difference only between the first and the last groups $(\mathrm{P}=0.01)$ (Table 2).

The family history of medical disorders and concomitant medical disorders were significantly more frequent in obese patients ( $41.7 \%$ for the two) than other groups.

The number of previous depressive episodes was higher in obese $(1.5 \pm 1.8)$ and in overweight patients $(1.1 \pm 1.7)$ than in those with normal weight $(0.8 \pm 1.1)$. The depressive polarity at index episode was also more frequent in obese and overweight patients $(21 \%$ and $16.2 \%$; respectively) than the other group (13\%), while, these differences were not significant (Table 2). 
Table 1. Subject characteristics.

\begin{tabular}{|c|c|c|c|c|}
\hline & Men $(n=79)$ & Women $(n=41)$ & $\mathbf{P}$ & Total population $(n=120)$ \\
\hline \multicolumn{5}{|c|}{ Characteristics } \\
\hline Age (years) & $39.6 \pm 10.9$ & $39.3 \pm 13.7$ & 0.24 & $39.5 \pm 11.9$ \\
\hline \multicolumn{5}{|c|}{$\boldsymbol{B M I}\left(\mathrm{kg} / \mathrm{m}^{2}\right)$} \\
\hline$<25, \mathrm{n}(\%)$ & $34(43)$ & $10(24.4)$ & & $44(36.7)$ \\
\hline$[25-30], \mathrm{n}(\%)$ & $25(31.6)$ & $12(29.3)$ & 0.04 & $37(30.8)$ \\
\hline$\geq 30, \mathrm{n}(\%)$ & $20(25.3)$ & $19(46.3)$ & & $39(32.5)$ \\
\hline Education years, mean $\pm \mathrm{SD}$ & $8.2 \pm 3.9$ & $7.1 \pm 5.3$ & 0.23 & $7.8 \pm 4.4$ \\
\hline Unemployed status, n (\%) & $25(31.6)$ & $26(63.4)$ & 0.001 & $51(42.5)$ \\
\hline Family history of medical disorders, n (\%) & $19(24.1)$ & $13(31.7)$ & 0.36 & $32(26.7)$ \\
\hline Concomitant medical disorders, $\mathrm{n}(\%)$ & $26(32.9)$ & $11(26.8)$ & 0.54 & $37(30.8)$ \\
\hline Age at onset, mean $\pm \mathrm{SD}$ & $30.3 \pm 9.9$ & $29.1 \pm 11.7$ & 0.58 & $29.9 \pm 10.5$ \\
\hline Total number of episodes, mean \pm SD & $5.1 \pm 3.3$ & $4.4 \pm 4.1$ & 0.30 & $4.9 \pm 3.6$ \\
\hline Number of depressive episodes, mean $\pm \mathrm{SD}$ & $1.0 \pm 1.3$ & $1.3 \pm 1.9$ & 0.49 & $1.1 \pm 1.5$ \\
\hline Number of manic episodes, mean $\pm \mathrm{SD}$ & $3.8 \pm 2.3$ & $2.8 \pm 2.6$ & 0.04 & $3.4 \pm 2.4$ \\
\hline Depressive polarity at index episode, $n(\%)$ & $13(16.5)$ & $8(19.5)$ & 0.67 & $21(17.5)$ \\
\hline Severity of index episode, $n(\%)$ & $65(87.8)$ & $32(82.1)$ & 0.40 & $97(80.8)$ \\
\hline Duration of illness, mean \pm SD & $12.6 \pm 7.9$ & $11.8 \pm 8.7$ & 0.58 & $12.3 \pm 8.2$ \\
\hline Number of lifetime suicide attempts, mean \pm SD & $0.09 \pm 0.29$ & $0.10 \pm 0.30$ & 0.89 & $0.09 \pm 0.30$ \\
\hline Number of prescribed drugs, mean $\pm \mathrm{SD}$ & $2.9 \pm 0.5$ & $2.8 \pm 0.8$ & 0.42 & $2.8 \pm 0.6$ \\
\hline Tobacco use, n (\%) & $72(91.1)$ & $1(2.4)$ & 0.001 & $73(60.8)$ \\
\hline \multirow[t]{2}{*}{ Alcohol use, $\mathrm{n}(\%)$} & $45(57)$ & $1(2.4)$ & 0.001 & $46(38.3)$ \\
\hline & \multicolumn{4}{|c|}{ Current treatment } \\
\hline Mood stabilizers, n (\%) & $59(74.7)$ & $25(61)$ & & $84(70)$ \\
\hline Valproic acid, n (\%) & $41(51.9)$ & $18(43.9)$ & & $59(49.2)$ \\
\hline Lithium, n (\%) & $6(7.6)$ & $3(7.3)$ & & $9(7.5)$ \\
\hline Carbamazepine, n (\%) & $7(8.9)$ & $3(7.3)$ & 0.57 & $10(8.3)$ \\
\hline Valproic acid/Lithium, n (\%) & $5(6.3)$ & $1(2.4)$ & & $6(5)$ \\
\hline Antipsychotics, n (\%) & $20(25.3)$ & $16(39)$ & & $36(30)$ \\
\hline
\end{tabular}

No significant difference was found between study groups for age at onset, the total number of episodes, number of manic episodes, severity of index episode and the number of lifetime suicide attempts.

The study of the therapeutic characteristics showed that was no significant difference in the study groups for the type of medication uses and the number of prescribed drugs. However, obesity and overweight were more frequent $(76.3 \%$ and $48.6 \%$; respectively) in patients taking valproic acid or lithium (Table 2).

\section{Discussion}

Our study showed that the prevalences of obesity and overweight in bipolar I patients were respectively $32.5 \%$ and $30.8 \%$. These findings were similar to those reported by Elmslie et al. (2000) and Fagiolini et al. (2002) (36\% and $32 \%)[14,15]$. However, higher values were reported by McElroy et al. (2004) (44\% and 20\%) [16]. Additionally, the prevalence of obesity greatly exceeded that found in the general population (20\%) [17]. 
Table 2. Differences in demographic, clinical and therapeutic characteristics between obese, overweight and neither obese or overweight patients.

\begin{tabular}{|c|c|c|c|c|}
\hline & $\begin{array}{c}\text { Normal weight } \\
\text { patients }(\mathrm{n}=44)\end{array}$ & $\begin{array}{l}\text { Overweight patients } \\
\quad(\mathrm{n}=37)\end{array}$ & $\begin{array}{l}\text { Obese patients } \\
\quad(\mathrm{n}=39)\end{array}$ & $\mathrm{p}$ \\
\hline \multicolumn{5}{|c|}{ Gender } \\
\hline Men, n (\%) & $34(43)$ & $25(31.6)$ & $20(25.3)^{*}$ & \multirow{2}{*}{0.04} \\
\hline Women, n (\%) & $10(24.4)$ & $12(29.3)$ & $19(46.3)$ & \\
\hline Age, mean $\pm \mathrm{SD}$ & $36.7 \pm 12.3$ & $41.3 \pm 11.2$ & $39.3 \pm 11.9$ & 0.21 \\
\hline Education years, mean $\pm \mathrm{SD}$ & $8.3 \pm 3.8$ & $6.9 \pm 4.8$ & $8.0 \pm 4.6$ & 0.35 \\
\hline Unemployed status, $\mathrm{n}(\%)$ & $17(36.9)$ & $17(45.9)$ & $18(47.1)$ & 0.57 \\
\hline Tobacco use, n (\%) & $31(67.4)$ & $23(62.2)$ & $19(50.0)$ & 0.25 \\
\hline Alcohol use, n (\%) & $20(43.5)$ & $15(40.5)$ & $11(28.9)$ & 0.36 \\
\hline Family history of medical disorders, $\mathrm{n}(\%)$ & $9(20.5)$ & $8(22.9)$ & $15(41.7)^{*}$ & 0.08 \\
\hline Concomitant medical disorders, $\mathrm{n}(\%)$ & $8(17.4)$ & $11(29.7)$ & $15(41.7)^{*}$ & 0.07 \\
\hline Age at onset, mean $\pm \mathrm{SD}$ & $27.9 \pm 10.5$ & $31.5 \pm 10.2$ & $30.3 \pm 10.8$ & 0.32 \\
\hline Total number of episodes, mean \pm SD & $4.4 \pm 2.9$ & $4.6 \pm 3.7$ & $5.6 \pm 4.1$ & 0.31 \\
\hline Number of depressive episodes, mean $\pm \mathrm{SD}$ & $0.8 \pm 1.1$ & $1.1 \pm 1.7$ & $1.5 \pm 1.8$ & 0.14 \\
\hline Number of manic episodes, mean $\pm \mathrm{SD}$ & $3.4 \pm 2.3$ & $3.1 \pm 2.4$ & $3.8 \pm 2.6$ & 0.51 \\
\hline Depressive polarity at index episode, $\mathrm{n}(\%)$ & $6(13.0)$ & $6(16.2)$ & $8(21.0)$ & 0.61 \\
\hline Severity of index episode, $\mathrm{n}(\%)$ & $33(75)$ & $32(86.5)$ & $32(82.1)$ & 0.38 \\
\hline Duration of illness, mean $\pm \mathrm{SD}$ & $9.6 \pm 7.7$ & $12.6 \pm 8.4$ & $14.8 \pm 7.8^{*}$ & 0.01 \\
\hline Number of lifetime suicide attempts, mean $\pm \mathrm{SD}$ & $0.07 \pm 0.3$ & $0.06 \pm 0.2$ & $0.2 \pm 0.4$ & 0.26 \\
\hline Number of prescribed drugs, mean $\pm \mathrm{SD}$ & $2.8 \pm 0.6$ & $2.9 \pm 0.7$ & $2.8 \pm 0.7$ & 0.87 \\
\hline \multicolumn{5}{|c|}{ Current treatment, $\mathrm{n}(\%)$} \\
\hline Valproic acid $(\mathrm{n}=59)$ & $20(33.9)$ & $15(25.4)$ & $24(40.7)$ & \\
\hline Lithium $(\mathrm{n}=9)$ & $1(11.1)$ & $3(33.3)$ & $5(55.6)$ & \\
\hline Carbamazepine $(\mathrm{n}=10)$ & $3(30)$ & $5(50)$ & $2(20)$ & 0.09 \\
\hline Valproic acid/Lithium $(\mathrm{n}=6)$ & $1(16.7)$ & $3(50)$ & $2(33.3)$ & \\
\hline Antipsychotics $(\mathrm{n}=36)$ & $19(52.8)$ & $11(30.6)$ & $6(16.7)$ & \\
\hline
\end{tabular}

*Significant difference between obese and normal weight patients $(\mathrm{p}<0.05)$.

Obesity in patients with bipolar I disorder thus constitutes a major public health problem and suggests that the development and testing of specific interventions that target the obesity epidemic in this particular population are urgently needed. Bipolar disorder and obesity both have a tremendous impact on the physical and mental well-being of affected individuals. Therefore, both illnesses should be treated with a coordinated intensive and multifaceted treatment [18].

Moreover, these results could be one of the missing factors in understanding the relationship between psychiatric disorders and increased cardiovascular risk. In fact, some studies have reported that psychiatric disorders, particularly bipolar disorder, are significantly associated with adverse cardiovascular events and coronary heart disease [19]. The mechanisms through which obesity leads to coronary heart disease remain hotly debated, but the accumulation, particularly, of visceral fat is widely favoured as the primary mechanism, leading, through the release of fatty acids and other mediators, to insulin resistance, dyslipidaemia, and a pro-inflammatory state. Insulin resistance is a primary factor in obesity-related disorders. By stimulating cellular glucose uptake and acting as an antilipolytic hormone, insulin may cause weight gain via direct effects on adipose tissue and influencing appetite through hypoglycemia. Leptin, which 
is synthesized by adipocytes, regulates appetite and body weight by activating leptin receptors in the satiety center of the hypothalamus. Adiponectin a hormone that plays a significant role in regulating insulin sensitivity is reduced in obesity and type 2 diabetes. Adiponectin is involved in lipid and glucose metabolism and insulin resistance. Administration of recombinant adiponectin stimulates glucose uptake and lipid oxidation in muscles while reducing lipid uptake and glucose synthesis in the liver, and increases the overall insulin resistance. In addition to these effects, adiponectin acts as an anti-inflammatory factor and reduces the risk of atherosclerosis, hypertension and coronary heart disease. Excess body fat, particularly abdominal visceral lipid deposition, is frequently accompanied by hypoadiponectinemia, which mediates the relationship between obesity and atherosclerotic vascular diseases [20,21].

Obesity was more frequent in women than men. These results are in consistent with the Wang et al. (2006) and McIntyre et al. (2006) studies [22,23]. In addition, this finding could be related to lack of exercise in women, indeed, we showed that approximately $60 \%$ of them were unemployed.

Our study showed that men were so much more likely to be smokers and alcoholic consumers than women. These results were in agreement with those reported by previous studies [19,24].

In addition, men have the highest number of manic episodes. This confirms the higher risk of cardiovascular diseases in men compared with women. In fact, previous studies suggested that mania, either directly (through factors intrinsic to illness) or indirectly (through other mediators or associated variables), increased the risk of cardiovascular disease [25].

No significant association was observed between obesity or overweight and age, year number of education, the employment status, tobacco status, and alcohol use. These results are in consistent with those reported by Fagiolini et al. (2002) [15]. In contrast, other studies showed that obesity had psychosocial consequences, including discrimination and stigmatization in multiple areas of daily life, such as health care, education and employment.

The study of clinical characteristics showed that the number of previous depressive episodes was higher in obese and in overweight patients than normal patients. Additionally, the depressive polarity at index episode was also more frequent in obese and overweight patients than the other group. Previous studies reported that patients who had depressive symptomatology were more likely to have excessive caloric and cholesterol intake, to smoke and to be inactive than non-depressed subjects. Another explanation might involve biological mechanisms: it is ascertained that hypothalamic-pituitary-adrenal (HPA) axis dysregulation and high cortisol blood levels lead to increasing visceral fat. HPA axis dysregulation has been a common finding in both unipolar and bipolar disorders; recently, some studies reported that increased cortisol blood levels correlated to the amount of intra-abdominal fat in major depression [26].

In addition, we showed that the duration of disease was longer in obese and in overweight patients than in those with normal weight. This could confirm the effect of bipolar disorder on the weight gain.

The family history of medical disorders and concomitant medical disorders was significantly more frequent in obese patients than in those with normal weight. Our findings are in agreement with previous studies [16,23, 27].

No significant difference was found between study groups for age at onset, the total number of episodes, severity of index episode and the number of lifetime suicide attempts. These results are in part in consistent with the Maina et al. (2008) study [26]. In contrast, Fagiolini et al. (2002) [15] showed that appetite, diet and energy expenditure are greatly influenced by both the polarity and acuity of an episode. Obesity may contribute to the severity of bipolar disorder by negatively impacting patients' general physical health and functioning, quality of life, self-esteem, and psychological well-being. Obese patients have an increased risk of sleep apnea, which causes sleep disruptions and may lead to mood destabilization in patients with bipolar disorder [18,28,29].

Additionally, no significant difference was found between study groups for a number of manic episodes. Our findings are in agreement with those reported by Fagiolini et al. (2003) [18].

About therapeutic characteristics, we found that obesity and overweight were more frequent $(76.3 \%$ and $48.6 \%$; respectively) in patients taking valproic acid or lithium. These findings are in line with those reported by De Hert et al. (2011) [8]. Moreover, Casey et al. (2005) [9] reported that lithium have been shown to stimulate appetite through different mechanisms. The "carbohydrate craving" that is thought to be one of the mechanisms of increased calorie intake in people taking lithium is well known. In addition, it is believed that valproate also stimulates weight gain through a variety of mechanisms, especially the development of insulin resistance and diabetes mellitus type. Valproic acid also decreases leptin secretion and mRNA levels in adipocytes in vitro, suggesting that valproic acid therapy may be associated with altered leptin homeostasis contributing to weight gain in vivo [30,31].

In conclusion, the prevalence of obesity and overweight in bipolar I patients was respectively $32.5 \%$ and $30.8 \%$. Obesity was significantly more frequent in women than men. The illness duration was significantly longer in obese patients than in those with normal weight. More- 
over, the family history of medical disorders and concomitant medical disorders were significantly more frequent in obese patients than in those with normal weight. However, any significant association between therapeutic characteristics and obesity or overweight was found. These results emphasize the need for specific treatment strategies and programs for weight control for these patients. Ideally, diet and exercise counselling should be provided to all bipolar disorder patients-before weight gain and definitely provided once weight gain has occurred. Exercise, diet, and individual or group behavioral therapy are the principal nonpharmacological means for inducing and maintaining weight loss. However, these may be particularly difficult to implement in individuals suffering from mood disorders.

\section{Acknowledgements}

The authors thank the patients and control subjects for their assistance in this study.

\section{REFERENCES}

[1] F. Marmol, "Lithium: Bipolar Disorder and Neurodegenerative Diseases Possible Cellular Mechanisms of the Therapeutic Effects of Lithium," Progress in Neuro-Psychopharmacology \& Biological Psychiatry, Vol. 32, No. 8, 2008, pp. 1761-1771. doi:10.1016/j.pnpbp.2008.08.012

[2] G. E. Simon, "Social and Economic Burden of Mood Disorders," Biological Psychiatry, Vol. 54, No. 3, 2003, pp. 208-215. doi:10.1016/S0006-3223(03)00420-7

[3] H. U. Wittchen, S. Muhlig and L. Pezawas, "Natural Course and Burden of Bipolar Disorders," The International Journal of Neuropsychopharmacology, Vol. 6, No. 2, 2003, pp. 145-154. doi:10.1017/S146114570300333X

[4] S. W. Woods, "The Economic Burden of Bipolar Disease," Journal of Clinical Psychiatry, Vol. 61, 2000, pp. 38-41.

[5] A. Ezzaher, D. Haj Mouhamed, A. Mechri, F. Neffati, W. Douki, L. Gaha and M. F. Najjar, "Association between Bipolar I Disorder and the L55M and Q192R Polymorphisms of the Paraoxonase 1 (PON1) Gene," Journal of Affective Disorders, Vol. 139, No. 1, 2012, pp. 12-17. doi:10.1016/j.jad.2011.06.029

[6] D. A. Revicki, L. S. Matza, E. Flood and A. Lloyd, "Bipolar Disorder and Health-Related Quality of Life: Review of Burden of Disease and Clinical Trials," Pharmacoeconomics, Vol. 23, 2005, pp. 583-594. doi:10.2165/00019053-200523060-00005

[7] R. J. Wyatt and I. Henter, "An Economic Evaluation of Manicdepressive Illness: 1991," Social Psychiatry and Psychiatric Epidemiology, Vol. 30, No. 5, 1995, pp. 213-219.

[8] M. De Hert, C. U. Correll, J. Bobes, M. Cetkovich-Bakmas, D. Cohen, I. Asai J. Detraux, S. Gautam, H. J. Möller, D. M. Ndetei, J. W. Newcomer, R. Uwakwe and S. Leucht, "Physical Illness in Patients with Severe Mental Disorders. I. Prevalence, Impact of Medications and
Disparities in Health Care," World Psychiatry, Vol. 10, 2011, pp. 52-77.

[9] D. E. Casey, "Metabolic Issues and Cardiovascular Disease in Patients with Psychiatric Disorders," American Journal of Medicine, Vol. 118, 2005, pp. 15-22.

[10] S. Malhotra and S. L. McElroy, "Medical Management of Obesity Associated with Mental Disorders," Journal of Clinical Psychiatry, Vol. 63, 2002, pp. 24-32.

[11] American Psychiatric Association, "Diagnostic and Statistical Manual of Mental Disorders," 4 Edition, American Psychiatric Association, Washington DC, 2004.

[12] World Health Organization, "Obesity: Preventing and Managing the Global Epidemic (publication WHO/NUT/ NCD/98.1)," WHO, Geneva, 1997.

[13] H. Pijil and A. E. Meinders, "Bodyweight Change as an Adverse Effect of Drug Treatment: Mechanisms and Management," Drug Safety, Vol. 14, 1996, pp. 329-342. doi:10.2165/00002018-199614050-00005

[14] J. L. Elmslie, J. T. Silverstone, J. L. Mann, S. M. Williams and S. E. Romans, "Prevalence of Overweight and Obesity in Bipolar Patients," Journal of Clinical Psychiatry, Vol. 61, 2000, pp. 179-184. doi:10.4088/JCP.v61n0306

[15] A. Fagiolini, E. Frank, P. R. Houck, A. G. Mallinger, H. A. Swartz, D. J. Buysse, H. Ombao and D. J. Kupfer, "Prevalence of Obesity and Weight Change during Treatment in Patients with Bipolar I Disorder," Journal of Clinical Psychiatry, Vol. 63, 2002, pp. 528-533. doi:10.4088/JCP.v63n0611

[16] S. L. McElroy, R. Kotwal, S. Malhotra, E. B. Nelson, P. E. Keck and C. B. Nemeroff, "Are Mood Disorders and Obesity Related? A Review for the Mental Health Professional," Journal of Clinical Psychiatry, Vol. 65, 2004, pp. 634-651. doi:10.4088/JCP.v65n0507

[17] F. G. Haddad, H. Brax, E. Zein and T. Abou el Hessen, "L'obésité et les Pathologies Associées dans un Centre de Soins au Liban," Journal Medical Libanais, Vol. 54, 2006, pp. 152-155.

[18] A. Fagiolini, D. J. Kupfer, P. R. Houck, D. M. Novick and E. Frank, "Obesity as a Correlate of Outcome in Patients with Bipolar I Disorder," American Journal of Medicine, Vol. 160, 2003, pp. 112-117.

[19] M. P. Garcia-Portilla, P. A. Saiz, M. T. Bascaran, S. Martinez, A. Benabarre, P. Sierra, P. Torres, J. M. Montes, M. Bousoño and J. Bobes, "Cardiovascular Risk in Patients with Bipolar Disorder," Journal of Affective Disorders, Vol. 115, No. 3, 2009, pp. 1-7. doi:10.1016/j.jad.2008.09.008

[20] A. Ezzaher, D. Haj Mouhamed, A. Mechri, F. Neffati, W. Douki, L. Gaha and M. F. Najjar, "Cardiovascular Risk in Tunisian Patients with Bipolar I Disorder," DyslipidemiaFrom Prevention to Treatment, Rijeka, 2012.

[21] J. Pinkney, "Implications of Obesity for Diabetes and Coronary Heart Disease in Clinical Practice," Britsh Journal of Diabetes and Vascular Disease, Vol. 1, No. 2, 2001, pp. 103-106. doi:10.1177/14746514010010020701

[22] P. W. Wang, G. S. Sachs, C. A. Zarate, L. B. Marangell, J. R. Calabrese, J. F. Goldberg, K. Sagduyu, S. Miyahara 
and T. A. Ketter, "Overweight and Obesity in Bipolar Disorders," Journal of Psychiatric Research, Vol. 40, No. 8, 2006, pp. 762-764. doi:10.1016/i.jpsychires.2006.01.007

[23] R. S. McIntyre, J. Z. Konarski, K. Wilkins, J. K. Soczynska and S. H. Kennedy, "Obesity in Bipolar Disorder and Major Depressive Disorder: Results from a National Community Health Survey on Mental Health and WellBeing," Canadian Journal of Psychiatry, Vol. 51, No. 5, 2006, pp. 274-280.

[24] P. J. R. Teixeira and F. L. Rocha, "The Prevalence of Metabolic Syndrome among Psychiatric Inpatients in Brazil," Brazilian Journal of Psychiatry, Vol. 29, No. 4, 2007, pp. 330-336.

[25] A. Ezzaher, D. Haj Mouhamed, A. Mechri, F. Neffati, W. Douki, L. Gaha and M. F. Najjar, "Lower Paraoxonase 1 Activity in Tunisian Bipolar I Patients," Annals of General Psychiatry, Vol. 9, 2010, p. 36. doi:10.1186/1744-859X-9-36

[26] G. Maina, V. Salvi, A. Vitalucci, V. D’Ambrosio and F. Bogetto, "Prevalence and Correlates of Overweight in Drug-Naïve Patients with Bipolar Disorder," Journal of
Affective Disorders, Vol. 110, No. 1-2, 2008, pp. 149-155. doi:10.1016/j.jad.2007.12.233

[27] A. J. Stunkard, M. S. Faith and K. C. Allison, "Depression and Obesity," Biological Psychiatry, Vol. 54, No. 3, 2003, pp. 330-337. doi:10.1016/S0006-3223(03)00608-5

[28] G. Cheymol, "Effects of Obesity on Pharmacokinetics Implications for Drug Therapy," Clinical Pharmacokinetics, Vol. 39, No. 3, 2000, pp. 215-231. doi:10.2165/00003088-200039030-00004

[29] D. T. Plante and J. W. Winkelman, "Sleep Disturbance in Bipolar Disorder: Therapeutic Implications," American Journal of Psychiatry, Vol. 165, No. 7, 2008, pp. 830-843. doi:10.1176/appi.ajp.2008.08010077

[30] A. Ezzaher, D. Haj Mouhamed, A. Mechri, F. Neffati, W. Douki, L. Gaha and M. F. Najjar, "Obesity and Dyslipidemia in Tunisian Bipolar Subjects," Annales de Biologie Clinique, Vol. 68, 2010, pp. 277-284.

[31] D. C. Lagace, R. S. Mcleod and M. W. Nachtigal, "Valproic Acid Inhibits Leptin Secretion and Reducesleptin Messenger Ribonucleic Acid Levels in Adipocytes," Endocrinology, Vol. 145, No. 12, 2004, p. 5493. doi:10.1210/en.2004-0877 